\section{ПРОБЛЕМА ВЗАИМОСВЯЗИ И МЕСТА ЭКОНОМИЧЕСКОЙ БЕЗОПАСНОСТИ В ЭКОНОМИЧЕСКОЙ ТЕОРИИ В СВЕТЕ ЭКОНОМИЧЕСКОЙ ИСТОРИИ И СОВРЕМЕННЫХ ТЕНДЕНЦИЙ РАЗВИТИЯ}

\begin{abstract}
Аннотация:
В статье анализируется связь современного развития периода финансово-экономического кризиса 2008-2009 ге. и нынешней пандемии COVID-19 как с историко-экономическими аналогами испанского гриппа 1918 г. и Великой депрессии 19291933 ге., так и с двумя этапами единого процесса возрастания роли трансакционных издержек в хозяйствах постиндустриального типа, выраженных процессами глобализации и текущей деглобализации. Выявляется прочная связь экономической безопасности с трансакционными издержками как с ее отсутствующим пока местом в экономической теории. Важнейшей особенностью исследования является опора на взгляды американского экономиста Н. Рубини, представленные как в книге, изданной после окончания кризиса, так и в современных прогнозах, касающихся дальнейшей деглобализации в результате последствий распространения COVID-19.
\end{abstract}

\section{Ключевые слова:}

пандемия, COVID-19, «испанка», экономическая безопасность, деглобализация, трансакционные издержки, глобализация, кризис.
THE PROBLEM

OF THE RELATIONSHIP AND PLACE OF ECONOMIC SECURITY

IN ECONOMIC THEORY IN THE LIGHT OF ECONOMIC HISTORY AND MODERN DEVELOPMENT TRENDS

Summary:

The article analyzes the relationship of modern development during the financial and economic crisis of 20082009, and the current COVID-19 pandemic, both with historical and economic analogues of the Spanish flu of 1918 and the period of the Great Depression of 19291933. The two stages of a single increase in the role of transaction costs in the post-industrial type of farms, expressed by the processes of globalization and modern deglobalization are also considered. The strong connection between economic security and transaction costs is being clarified as with its so far lacking place in economic theory. The most important feature of the analysis is the reliance on the views of the American economist, Nuriel Rubini, expressed both in the book he published after the crisis ended and in modern forecasts regarding further deglobalization as a result of the consequences of the spread of COVID-19.

Keywords: pandemic, COVID-19, Spanish flu, economic security, deglobalization, transaction costs, globalization, crisis.

Серьезные изменения в современном мире экономических взаимосвязей и условий развития бизнеса раскололи саму экономическую историю на период до событий пандемии COVID-19 и после них, на данный момент прочно вплетая историю в каждый миг современности как этап перелома в экономических тенденциях. Однако каковы эти тенденции текущего периода, а также в чем состоит перелом в экономическом развитии как с позиции экономической теории, так и с точки зрения ее рецептов для практики хозяйствования - эти вопросы могут быть лишь гипотетически в качестве контуров обрисованы на самом этапе прохождения перелома. Тем не менее видные экономисты современности, доказавшие свои прогнозные способности, к каковым, в частности, относится предсказавший кризис 2008-2009 гг. Нуриэль Рубини, позволяют понять эти тенденции, касающиеся упомянутого перелома, и в настоящий момент. Цель исследования заключается в том, чтобы вслед за Н. Рубини показать, каковы эти тенденции, как неразрывно они связаны с предшествующим историко-экономическим развитием последнего десятилетия, а также какую роль в них играет экономическая безопасность (не затрагиваемая Н. Рубини терминологически, но при этом охватываемая им в рассуждениях содержательно).

С одной стороны, опыт предшествовавшей экономической истории столетней давности, связанный с влиянием распространения испанского гриппа («испанки») 1918 г. на глобальное экономическое развитие, показывает неизменность основных тенденций эволюции хозяйства. Как пояснил в работе 2007 г. американский экономист Т.А. Гарретт, влияние пандемии гриппа 1918 г. на изменение прошлых тенденций и дальнейшее экономическое развитие можно признать малоисследованной областью и определить ее относительно слабую роль, больше с краткосрочными масштабами воздействия. Временный всплеск развития отраслей обеспечения продуктами 
здравоохранения, возникший на фроне резкого и также временного сужения сферы услуг и развлечений, дефицит труда с увеличением доходов и сокращение потенциала человеческого капитала для рождавшихся в период пандемии и сразу после нее - в основном это все зафиксированные существенные последствия распространения данного заболевания [1, р. 21].

Таким образом, ключевые параметры интернационализации хозяйства, характерные для периода до появления биологического препятствия перед нормальным ходом экономического развития, не только не были повернуты вспять внезапно возникшим барьером, но и оказались дополнены в дальнейшем новой реальностью. Она касается первого появления глобализации в части взаимосвязи финансовых рынков основных передовых стран того времени как первичного полувекового этапа будущей глобализации всего мирового хозяйства.

С другой стороны, именно первое появление глобализации в виде ее финансово-рыночной формы стало прологом к первому глобальному кризису в регуляции хозяйства, связанному с периодом Великой депрессии в США 1929-1933 гг., с проявлением этого кризиса в других передовых странах того времени в силу глобализованности финансовых рынков. Кризис оказался глобальным настолько, что многие ведущие государства были отброшены в уровне экономического развития на 20-30 лет назад, и это неслучайно.

Во-первых, события Великой депрессии четко обозначили кризисный источник, обрушивший взаимосвязанные глобализованные фондовые рынки за счет крупной проблемы в одном из них. В то время в этом качестве выступила связь спекуляции на фондовом рынке с кредитованием как опорой ее операций, мгновенно и глобально отразившаяся (из-за возникшей ранее финансовой глобализации) на всех участниках рынка за счет сомнения банкиров в возврате вложенных средств при падении курса акций.

Казалось бы, уже в этом первом срабатывании со всей отчетливостью видна роль экономической безопасности фондовой биржи на фоне слишком тесной корреляции ее операций с кредитным блоком экономики. Однако вывод был усвоен лишь относительно прямого основания финансово-спекулятивных сделок и не был проанализирован на предмет иных возможных тесных сцеплений интересов банковского сектора с фондовым рынком. Напротив, прочная финансовая взаимосвязь не только не исчезла, но и обросла отдельными проявлениями внутренних тенденций, влиявших на периодичность общеэкономических кризисов вслед за финансовым сектором. Именно эту особенность кризисов на базе взаимосвязи финансовых рынков исследовал Н. Рубини в книге «Кризисная экономика». Он показывал ее как своего рода «белого лебедя», т. е. видимую часть влияния на фрормирование кризисности в экономической системе (в отличие от «черного лебедя» - как непредсказуемо возникающих, подобно торнадо, событий), определяемую скорее как «известное неизвестное». Причем, по Н. Рубини, такая ожидаемая видимая составляющая кризисных предысторий способна достичь переломного «момента Мински», за которым следует крах [2] («момент Мински» описывает философию пессимистического настроя американского экономиста Х. Мински по поводу стабильности финансовых рынков).

Н. Рубини в связи с этим писал: «За прошедшие десятилетия финансовые рынки стали еще более интегрированными и взаимозависимыми. Действительно, во время недавнего кризиса сложную сеть заимствований и кредитов, которые связывали воедино международную финансовую систему, было почти невозможно полностью понять, а тем более распутать. Фактически мало кто, вероятно, понимал, что стресс на рынке репо или коммерческих бумаг в одной стране может быть быстро передан в другое место. Хотя были некоторые кризисы, которые пересекали национальные границы, ни один из них не приблизился к соперничеству с Великой депрессией; понимание того, как мировая фринансовая система могла и будет разрушаться, было ограниченным» [3].

Как видно, именно взаимозависимость финансовых рынков послужила предсказательной базой для выводов Н. Рубини относительного предстоявшего кризиса 2008-2009 гг., источник которого вновь, как и ранее в период Великой депрессии 1929-1933 гг., был обусловлен четкой связью фондового рынка и кредитной системы. В части случившегося чуть более 10 лет назад глобального финансово-экономического кризиса такая связь возникла из-за резкого увеличения деривативного фондового капитала, образовавшегося через рынок ипотечного жилья, и состояла она во взаимозависимости развития рынка деривативов и роста премиальных и «парашютных» выплат отвечавшим за эти рынки руководителям банковского сектора. Снова, как и 80 лет назад, корреляция кредитной системы с фондовым рынком взорвала экономические взаимосвязи системы, сформировав «момент Мински» по череде банковских крахов и дальнейшему влиянию на экономику передовых стран мира, а через них - и на остальные государства.

Во-вторых, события Великой депрессии продемонстрировали еще одну специфическую черту развития экономики, касающуюся динамики в период кризиса особого типа издержек в экономике фрирм, впервые осмысленных после выхода из глобального кризиса Р. Коузом [4]. Увели- 
чение данных издержек - естественная часть реакции экономики фрирм на любые крупные кризисы, поскольку с неизбежностью приводят к масштабной перестройке взаимосвязей компаний. Например, это касается как биологических препятствий к экономическому росту типа пандемий «испанки» 1918 г. или современной COVID-19, так и двух сравнимых глобальных кризисов - недавнего 2008-2009 гг. или времен Великой депрессии. Каждый из этих кризисов обусловливает приспособление большинства фирм к неизбежности потерь части старых связей, уже занятых под новые цепочки связей с другими фирмами. Именно поэтому подобные масштабные изменения в хозяйстве неминуемо актуализируют коррелирующую с возрастанием трансакционных издержек роль экономической безопасности в функционировании как бизнеса, так и национальной экономики в целом.

Относительно периода «испанки» 1918 г. можно отметить, что роль данных издержек не стала для экономики переломным моментом лишь из-за сохранявшегося потенциала не пройденного этапа функционирования индустрии по принципу «печки» (чем существеннее загрузка природных ресурсов в индустриальную «топку» их переработки, тем больше результат на выходе из индустриальной «печи»). Напротив, в ситуации приоритета трансакционных издержек для условий развития постиндустриальных хозяйств такие издержки напрямую влияют на тенденцию возрастания значения экономической безопасности фрирм и национального хозяйства, сфрормированную еще с периода достижения индустриальной системой пределов развития с начала 1970-х гг.

Именно на данный недостаточно познанный факт связи увеличения значимости трансакционных издержек со строго соответствующей возрастающей ролью экономической безопасности как фирм, так и национальных хозяйств следует обратить внимание как на принципиальный момент для понимания взаимосвязи экономической безопасности с экономической теорией. В этом состоит особый имеющийся в науке парадокс, проявляющийся в том, что экономическая безопасность, став актуальным звеном экономического анализа начала нового столетия, не нашла пока отражения в экономической теории, оставаясь ее частным прикладным приложением. В немалой степени такому парадоксу способствовала неверная трактовка экономической безопасности, сформулированная на первом постиндустриальном этапе повышения значения трансакционных издержек, как продолжения тенденций индустриального этапа по дальнейшей глобализации хозяйственных связей в микро- и макроэкономике.

Возобладавшая в исследованиях и нормативно-правовых закреплениях трактовка экономической безопасности как состояния защищенности от каких-либо угроз, появившаяся в рамках макроэкономического подхода, как подчеркивает С.А. Афонцев, способна превращать саму экономическую безопасность «в общую теорию всего» [5, с. 325], что подразумевает риски в подмене самой экономической безопасностью всей экономической теории. Одновременно с этим в микроэкономическом подходе возобладала иная интерпретация, фрактически заменяющая экономической безопасностью оценки экономической эффективности при толковании безопасности как наличия конкурентных преимуществ либо состояния наиболее эффективного использования ресурсов, которые в лучшем случае авторы соединяют с целевым предназначением функционала данной экономической эффективности для преодоления угроз.

Таким образом, вместо соответствующей прочной связи экономической безопасности с трансакционными издержками, при которой она может трактоваться как состояние соответствия условий развития хозяйства его долгосрочной устойчивости на рынке, иные толкования уводят в сторону от подлинной роли экономической безопасности в экономической теории и практике. Более того, такие «иные трактовки» не только делают современный этап деглобализации (повторный после глобализации период усиления роли данных издержек) отказом от прогрессивного развития, но еще и противоречат тенденциям к дальнейшей деглобализации как логичным следствиям нынешней пандемии COVID-19, описываемым H. Рубини [6]. Предложенное определение экономической безопасности касается системы контрактов о необходимых поставках «ресурсов обеспечения» долгосрочного развития и о согласии регуляторов на достаточность организации этих ресурсов в хозяйстве. Одновременно экономическая безопасность есть неотъемлемый элемент и макроэкономики, причем в триаде, где два других связанных компонента - экономический рост и развитие.

\section{Ссылки:}

1. Garrett T.A. Economic Effects of the 1918 Influenza Pandemic: Implications for a Modern-day Pandemic [Электронный pecypc] // Federal Reserve Bank of St. Louis. 2007. Nov. URL: https://www.stlouisfed.org/ /media/files/pdfs/community-development/research-reports/pandemic flu report.pdf (дата обращения: 29.06.2020).

2. Рубини Н. «Белые лебеди» 2020 г. Каких экономических, финансовых, политических и геополитических потрясений ожидать в этом году [Электронный ресурс] // День. 2020. 25 февр. URL: http://day.kyiv.ua/ru/article/den-planety/belyelebedi-2020-goda (дата обращения: 29.06.2020) ; Roubini N. The White Swans of 2020 [Электронный ресурс] // Nourielroubini.com. 2020. Feb. 17. URL: https://nourielroubini.com/the-white-swans-of-2020 (дата обращения: 29.06.2020). 
3. Roubini N., Mihm S. Crisis Economics: A Crash Course in the Future of Finance. N. Y., 2010. Ch. 5. Global Pandemics. P. 115-135.

4. Coase R. The Problem of Social Cost // Journal of Law and Economics. 1960. Vol. 3, no. 1. P. 1-44.

5. Афонцев С.А. Политические рынки и экономическая политика. М., 2015. 384 с.

6. Нуриэль Рубини: Надвигается «очень Великая депрессия» 2020-х гг. [Электронный ресурс] // Хвиля : информационно-аналитический портал. 2020. 1 мая. URL: https://hvylya.net/analytics/206227-nuriel-rubini-nadvigaetsya-ochen-velikaya-depressiya-2020-h-godov (дата обращения: 29.06.2020).

Редактор: Тюлюкова Мария Олеговна Переводчик: Кочетова Дарья Андреевна 